\title{
Eco-Friendly Synthesis of Carbon Nanoparticles by Laser Ablation in Water and Evaluation of Their Antibacterial Activity
}

\author{
Faizah A. AlMalki, ${ }^{1}$ Khawla S. Khashan $\mathbb{D}^{2}{ }^{2}$ Majid S. Jabir $\mathbb{D}^{3}$ Aseel A. Hadi ${ }^{\circ}{ }^{2}$ \\ Ghassan M. Sulaiman $\mathbb{D}^{,}{ }^{3}$ Farah A. Abdulameer, ${ }^{4}$ Salim Albukhaty, ${ }^{5}$ Hassan Al-Karagoly, ${ }^{6}$ \\ and Jawaher Albaqami ${ }^{1}$ \\ ${ }^{1}$ Department of Biology, College of Science, Taif University, P.O. Box 11099, Taif 21944, Saudi Arabia \\ ${ }^{2}$ Division of Laser Sciences and Technology, Department of Applied Sciences, University of Technology, Baghdad 10066, Iraq \\ ${ }^{3}$ Division of Biotechnology, Department of Applied Sciences, University of Technology, Baghdad 10066, Iraq \\ ${ }^{4}$ College of Health and Medical Techniques, Gilgamesh Ahliya University, Baghdad, Iraq \\ ${ }^{5}$ Department of Basic Science, College of Nursing, University of Misan, Maysan, Iraq \\ ${ }^{6}$ Department of Internal and Preventive Medicine, College of Veterinary Medicine, University of Al-Qadisiyah, Iraq
}

Correspondence should be addressed to Khawla S. Khashan; 100082@uotechnology.edu.iq

and Ghassan M. Sulaiman; ghassan.m.sulaiman@uotechnology.edu.iq

Received 3 November 2021; Revised 15 January 2022; Accepted 20 January 2022; Published 7 February 2022

Academic Editor: Bo Tan

Copyright (c) 2022 Faizah A. AlMalki et al. This is an open access article distributed under the Creative Commons Attribution License, which permits unrestricted use, distribution, and reproduction in any medium, provided the original work is properly cited.

\begin{abstract}
Carbon nanomaterials are ground-breaking two-dimensional materials with a wide range of applications because of their unique properties, which include excellent optical, electrical, thermal, and mechanical capabilities; biocompatibility; and inexpensive large-scale production costs. In this study, carbon nanostructural materials (CNMs) were effectively generated using a pulsed laser ablation method on a graphite target immersed in deionized water, and their cytotoxicity and antibacterial activities were evaluated. Lasing pulse duration, ns $(1064 \mathrm{~nm})$ with different laser energies $(60-220 \mathrm{~mJ})$, was employed for irradiating the target. The formation of CNMs was analyzed using Fourier transform infrared spectroscopy, which demonstrated that $\mathrm{C}-\mathrm{H}$, $\mathrm{C}-\mathrm{C}, \mathrm{C}-\mathrm{O}$, and $\mathrm{C}=\mathrm{C}$ bonds were successfully formed. TEM micrographs observed $\mathrm{CNM}$ formation with a spherical shape and size ranging from 20 to $90 \mathrm{~nm}$. The absorbance was measured using UV-Vis spectroscopy; it increased with increasing laser energy showing two broad shoulders around 210 and $305 \mathrm{~nm}$. Thereafter, the antibacterial activity was tested against Escherichia coli and Staphylococcus aureus using the agar method. The results indicated that CNMs fabricated at laser energy $220 \mathrm{~mJ}$ have the highest activity against both strains and have presented inhibition zone (IZ) of about $34 \pm 1.0 \mathrm{~mm}$ in $\mathrm{S}$. aureus and $31 \pm 1.5 \mathrm{~mm}$ for E. coli. A comparison with CNMs prepared at $160 \mathrm{~mJ}$ showed an IZ of $14 \mathrm{~mm}$ for S. aureus and of $12 \mathrm{~mm}$ for $E$. coli due to synergistic impact, while the cellular material release analysis displayed increased release with respect to the time of exposure due to inhibition of bacterial growth.
\end{abstract}

\section{Introduction}

Nanostructured materials have recently attracted scientists' interest due to their distinct properties when compared to bulk materials [1]. Therefore, these nanomaterials can be applied in different fields including solar cell [2], optoelectronic [3], catalyst [4], sensor [5], and medicines [6]. Different production techniques have been used for nanostructure material formation such as hydrothermal synthesis [7, 8], chemical vapor deposition method [9], chemical method [10], spray pyrolysis [11], sputtering [12], and sol-gel [13] which relies on the requirements and the kind of materials. Among them, pulsed laser ablation in liquid has been employed in creating a wide range of nanostructured materials with different shapes and sizes, related to laser features such as energy, wavelength, and pulse duration [14-16]. 


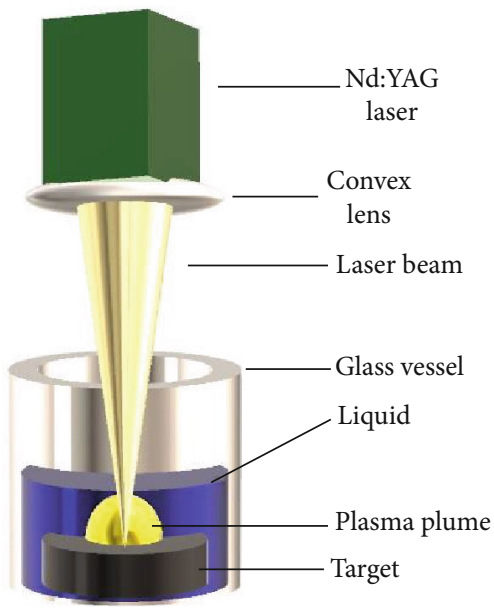

Figure 1: A schematic set up for CNM synthesis via PLAL.

Carbon nanostructure materials (CNMs) have gotten a lot of attention recently because of their important function in a variety of industries [17-20]. This is due to their exceptional properties, which include being nontoxic, biocompatible, photochemically stable, and emitting intense and sizedependent optical photoluminescence. Furthermore, due to their easy surface functional groups such as carbonyl, alcoholic hydroxyl, amine, ester, and amide, CNMs can be applied as therapeutic agents [18]. Many researches have prepared these materials and used them in different applications. Escobar-Alarcon et al. [21] used the $532 \mathrm{~nm} \mathrm{Nd:} \mathrm{YAG} \mathrm{laser} \mathrm{to}$ ablate graphite target in deionized water and displayed the effect of laser fluence on colloidal properties. Researchers have recently focused their efforts on various CNM synthesis methods and medicinal applications such as anticancer activity and side effects $[22,23]$. Numerous studies have been conducted on the effect of nanomaterials on bacteria, but more research is needed to better understand the effects of CMNs on pathogenic bacteria, as well as the mechanism of CMNs' exact effect on bacteria. As a result, the goal of this study was to use the pure laser ablation liquid (PLAL) technique to synthesize CNMs at various concentrations and examine their cytotoxic effect on cell viability as well as their antibacterial activities.

\section{Materials and Methods}

2.1. Preparation of CNMs. A Q-switched pulsed Nd: YAG laser operating at $1064 \mathrm{~nm}$ wavelength with pulse repetition rate $1 \mathrm{~Hz}$ and pulse duration $9 \mathrm{~ns}$ (laser beam spot size $=2.06$ $\mathrm{mm}$ ) was utilized for ablating the graphite target submerged in the deionized water $(\mathrm{D}-\mathrm{W})$. The graphite pellet of a purity of $99.91 \%$ (from national spectroscopic electrodes co.) with diameter $=5 \mathrm{~mm}$ was put at the bottom of a glass vessel containing $3 \mathrm{~mL}$ of $\mathrm{D}-\mathrm{W}$. The laser energy was ranging from 60 to $220 \mathrm{~mJ}$ at 75 pulses. Figure 1 shows the experimental setup of the preparation process. The target was rotated continuously during the ablation process to have uniform ablation.
2.2. Characterization of CNMs. The mass concentration was calculated according to the following equation:

$$
\text { Mass concentration }=\frac{\Delta M}{\text { Liquid volume }}
$$

where $\Delta \mathrm{M}$ is the amount of ablated target mass $(\Delta M)$ which was calculated by the difference between the weight of the target before $(\mathrm{m} 1)$ and after $(\mathrm{m} 2)$ the laser ablation for each condition [16]. The vibrational structure was explored via Fourier transform infrared (FTIR, Shimadzu, Japan) spectroscopy investigation. This study was done in the spectral wavelength ranging $2000-400 \mathrm{~cm}^{-1}$ in a room temperature. The shape and size of prepared samples were determined using a Transmission Electron Microscope (TEM) (H-7100, Hitachi Ltd., Tokyo, Japan). Double-beam ultravioletvisible (UV-Vis, Shimadzu, Japan) spectroscopy was employed to measure the absorption spectrum peak in the range between 200 and $400 \mathrm{~nm}$ at ambient temperature into a quartz cell with $1 \mathrm{~cm}$ optical path.

2.3. Antibacterial Activity of CNMs. CNMs were tested for their antibacterial properties against E. coli and S. aureus using agar well diffusion assay. About $20 \mathrm{~mL}$ of Muller-Hinton $(\mathrm{MH})$ agar was poured into sterile Petri dishes. The bacterial species were collected from their stock cultures using a sterile wire loop. After spreading E. coli and S. aureus, using the tips of a sterile micropipette, wells with a diameter of $6 \mathrm{~mm}$ were punched in the agar media. Then, after combining them with a vortex, CNMs at different conditions 60, 80, 160 , and $220 \mathrm{~mJ}$ were added to the wells. The cultured plates were incubated for $24 \mathrm{hr}$ at $37^{\circ} \mathrm{C}$. The antibacterial activity of CNMs was measured by measuring the diameter of the inhibition zone. All tests were performed three times, with deionized distilled water serving as a negative control.

2.4. Test of Cellular Material Release. The sterile media of peptone water were used to display the test of cellular material release; the medium was injected with the two strains. CNMs were introduced to the tubes after a 24-hour 


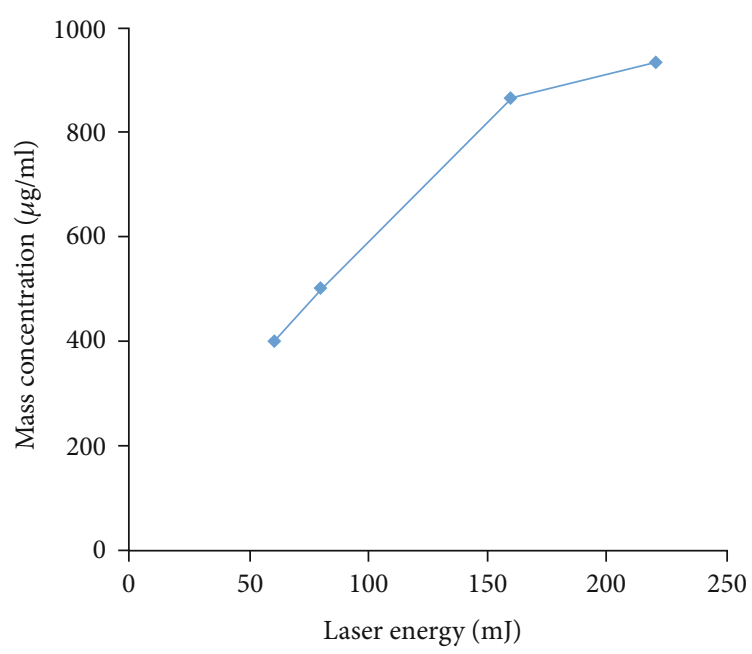

Figure 2: CNM mass concentration synthesized via PLAL at various laser energies.

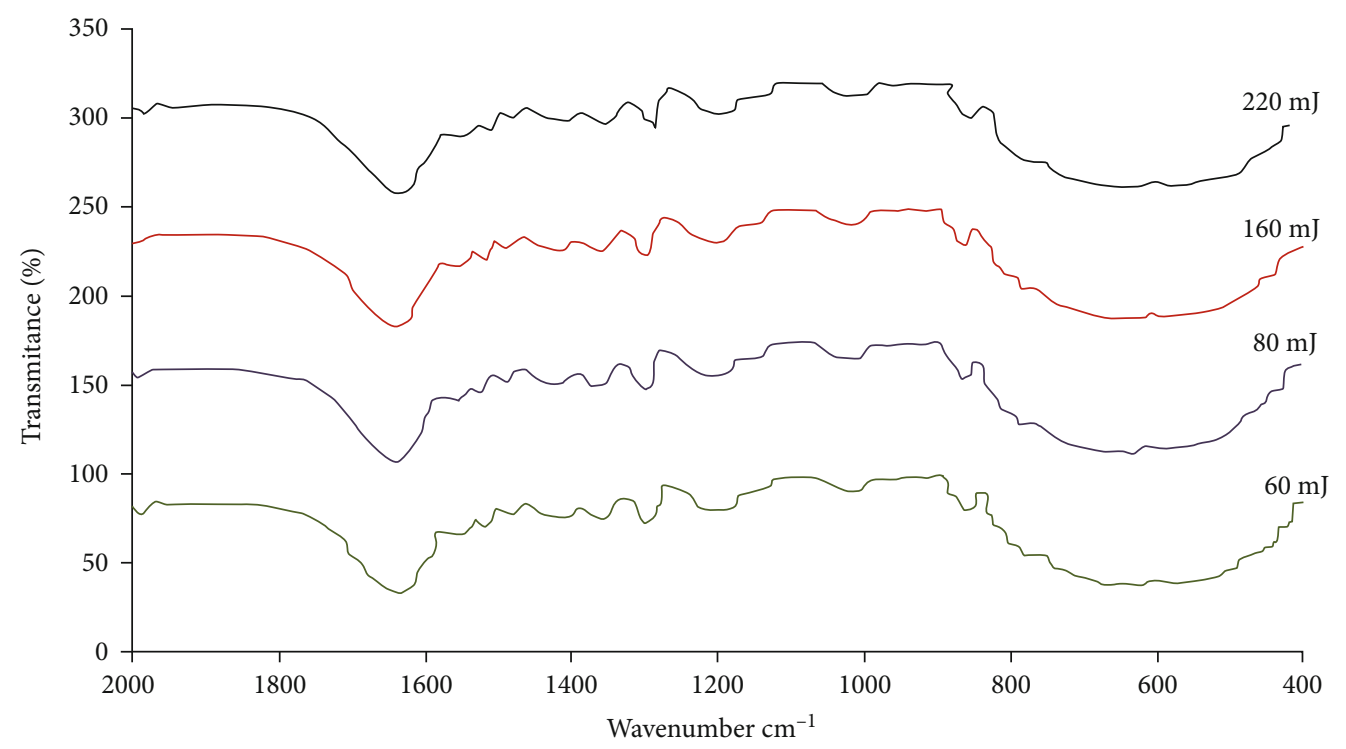

FIgURE 3: FTIR spectra of CNMs produced by PLAL at various laser energies.

incubation period. After becoming treated for 0, 30, 60, 120, 180 , and 240 minutes, the samples were then centrifuged for three minutes at $3500 \mathrm{RPM}$, and the optical absorbance peak was measured at $550 \mathrm{~nm}$. The findings of the examination were recorded as a percentage of absorbance of cellular material at a wavelength of $550 \mathrm{~nm}$ throughout time.

2.5. Statistical Analysis. Statistical Package for the Social Sciences (SPSS) was utilized to analyze data. The mean \pm standard deviation of triplicate measurements and a oneway variance analysis (ANOVA) were used to conduct data analysis, and the significant difference was set at $p \leq 0.05$.

\section{Results and Discussion}

Figure 2 shows the mass concentration of CNMs as a function of the laser energy, these CNMs were generated via
PLAL of graphite in DIW at 75 pulses with change of the laser energy from 60 to $220 \mathrm{~mJ}$. It was found that the concentration of NPs increases as laser energy increases, meaning that more heat can be transferred to the target, resulting in an increase in surface temperature and the evaporation of a significant amount of surface target. A nonlinear scenario emerged when the laser pulse energy exceeded $160 \mathrm{~mJ}$. The concentration of CNMs will no longer increase linearly with laser energy. An increase in mass rate, suggesting a shift in the vaporization region, could be linked to the presence of a large number of target droplets in the plume created in the surrounding liquid [24].

Figure 3 displays the spectra of FTIR of CNMs prepared with various laser energies, from all spectra; a peak at $\sim 1630 \mathrm{~cm}^{-1}$ was indicated for stretching vibration of $\mathrm{C}=\mathrm{C}$, while the $\mathrm{C}-\mathrm{C}$ stretching vibration bond peak was observed at $\sim 1290 \mathrm{~cm}^{-1}$ [25]. These findings revealed the production 

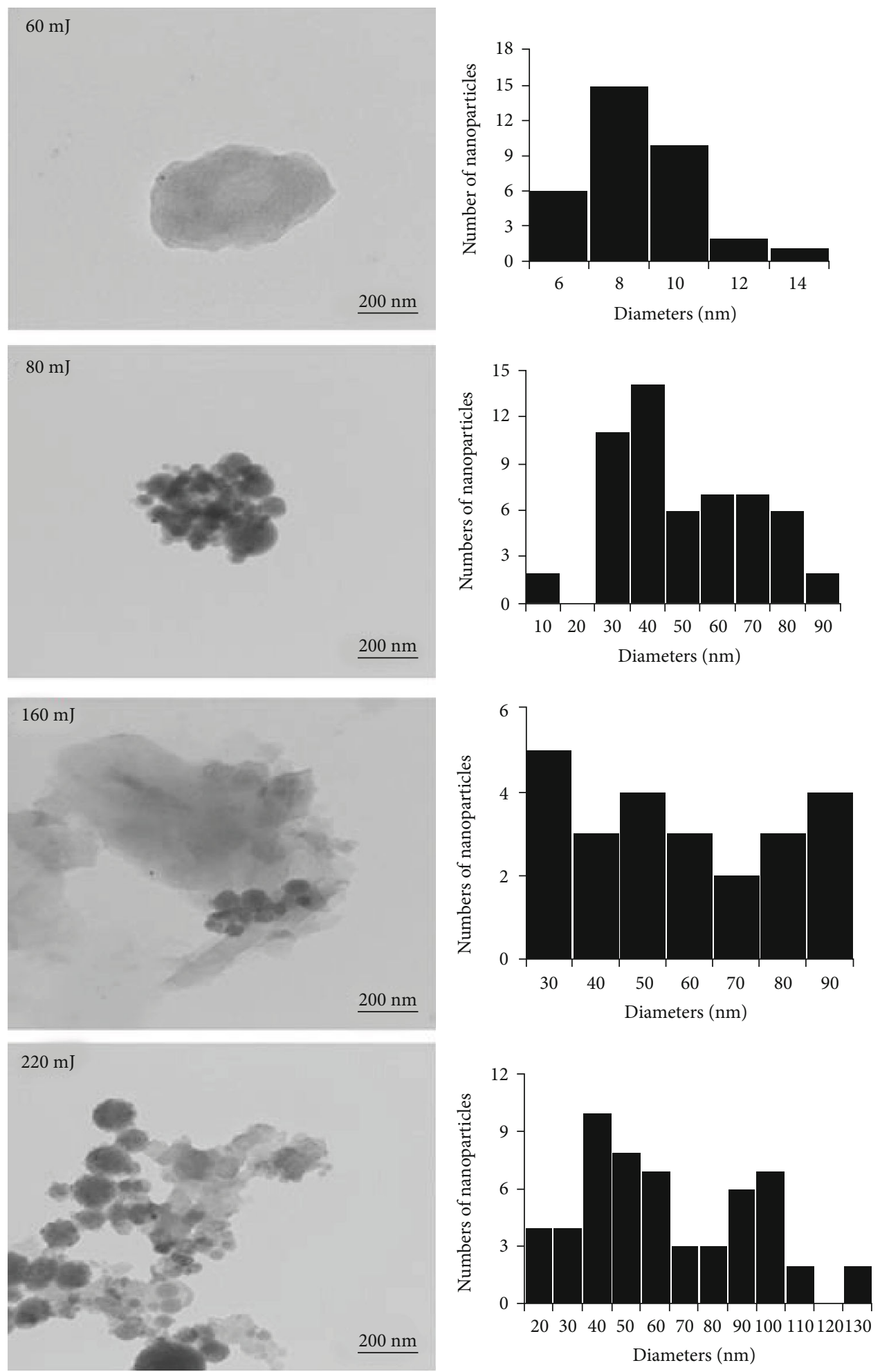

FIgURE 4: TEM micrographs and size distribution of CNMs synthesized with different laser energies.

of carboxyl groups in the obtained CNMs. Furthermore, there is a broad and vigorous characteristic band around $715 \mathrm{~cm}^{-1}$. Furthermore, there is a broad and vigorous distinctive band around $715 \mathrm{~cm}^{-1}$ [26]; this is analogous to the aromatic plane folding of $\mathrm{C}-\mathrm{H}$ that occurs in water between carbon and hydrogen atoms, and a weak band of $\mathrm{C}-\mathrm{OH}$ stretching vibration group has appeared at $\sim 1346 \mathrm{~cm}^{-1}$. Finally, a small peak of C-O stretching mode was shown at $\sim 1174 \mathrm{~cm}^{-1}$ [27]. 
Figure 4 shows TEM micrographs and size distributions for CNMs created by PLAL at various laser energies. It was observed that CNMs prepared at $60 \mathrm{~mJ}$ have a spherical shape form with a dimension of 5-13 nm. Additional TEM micrographs show a significant appearance of nanomaterial (CNM) aggregation at higher laser intensity due to the electrostatic attractive attraction between them, which was produced due to the electric double layer on the nanomaterials' surface [28]. Pulsed laser ablation of graphite is a photothermal operation. The increase in target temperature caused by the laser pulse results in melting of material and, finally, ejection of ablated amount from the target's surface. In the case of graphite, this can result in the ejection of CNMs. Because of the liquid environment effect, the surrounding liquid medium has a substantial effect of confinement, which slows the rate of expansion. As a result of this hit, a thick species forms inside the plasma, which is accompanied by a rapid drop in heat. The strong heat diffusion of these very compact molecules can cause collisions, aggregations, and the synthesis of new structures. Also, the micrographs proved that at low energy, small nanomaterials with narrow size-distribution were obtained; but at high energy, the nanoparticle size distribution width clearly increased. Low energy promotes material eradication via evaporation, resulting in the formation of nanomaterials from evaporated atoms with a uniform size distribution.

The produced carbon nanomaterials synthesized by PLAL had their UV-visible absorption spectra measured at wavelengths spanning from 200 to $500 \mathrm{~nm}$. The spectrum of absorption peaks of CNMs produced at various laser intensities is illustrated in Figure 5. The UV-visible spectrum of colloidal CNMs revealed a continuous spectrum between 200 and $420 \mathrm{~nm}$, with two distinct shoulders approximately 210 and $305 \mathrm{~nm}$ related to $\pi \rightarrow \pi *$ of $\mathrm{C}-\mathrm{C}$ transition and $\pi \rightarrow \pi *$ of $\mathrm{C}=\mathrm{O}$ electronic transition. The carboxyl group was created on the surface of CNMs during the pulsed laser ablation in D-W, whereas C-C could be synthesized immediately from the graphite core [29].

It is noticeable that the UV-Vis absorption spectrum increased with increased laser energy, indicating that the synthesis rate of CNMs increased with laser energy, which is consistent with the concentration analysis investigations. Furthermore, due to the saturation condition of NP suspensions, absorption of CNMs produced at $160 \mathrm{~mJ}$ was higher than that of CNMs produced at $220 \mathrm{~mJ}$ (Figure 5). These findings demonstrated that laser energy alters the concentration and size of CNMs in colloidal suspensions [30]. Figure 6 illustrates the antibacterial effect of CNMs generated by PLA at various laser energies against E. coli and S. aureus using the agar well diffusion approach.

The inhibitory effect on the bacterial growth of CNMs increased as their concentration increased, with an IZ of about $34 \pm 1.0 \mathrm{~mm}$ in $S$. aureus and $31 \pm 1.5 \mathrm{~mm}$ for $E$. coli. CNMs created with higher laser intensity demonstrated a stronger antibacterial effect against both bacterial strains. Interestingly, rather than the size of NPs, the concentration of CNMs was the key component that controlled the antibacterial action in the current investigation. Although the size of CNMs made at $220 \mathrm{~mJ}$ was larger than that of CNMs

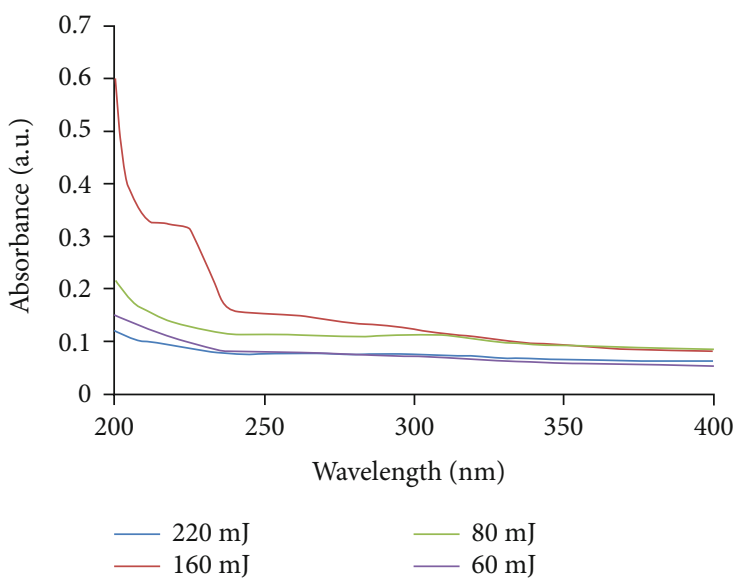

FIgURE 5: UV-visible spectra of CNMs fabricated by PLAL at different energies.

made at lower laser energies, the greater inhibitory effect was attributed to the high concentration of such energy.

It was also noticeable that these CNMs had the greatest antibacterial effect against gram-positive bacteria, but gram-negative bacteria appeared to be more resistant to a wider spectrum of antimicrobial agents than grampositive bacteria. Gram-negative bacteria are more resistant to antibiotics because their cell walls are more complicated. The cell wall of gram-negative bacteria is made up of a thin peptidoglycan layer that is covered by an outer membrane. The gram-negative bacteria's outer membrane is generally resistant to hydrophobic chemicals like NPs [31].

The antimicrobial property of nanomaterials is influenced by a variety of variables, including their size, surface functionalization, composition, and bacterial strains. The size of carbon nanostructure materials is one of the most important factors influencing their antibacterial impact; that is, increasing the surface area of nanomaterials by reducing their size improves their interaction with microscopic organisms [19]. Both physical and chemical procedures are combined in the antibacterial activities of CNMs. These nanomaterials can cause structural and morphological damage to the cell membrane of bacterial strains in the physical realm, while chemical interactions between carbon nanomaterials and bacteria's surfaces may result in the creation of harmful chemicals such as reactive oxygen species (ROS), putting the organism under oxidative stress [32]. Figure 7 shows the absorption of cellular material release analysis of E. coli and S. aureus exposed to CNMs with 60, 160, and $200 \mathrm{~mJ}$ laser energy. The optical density of bacterial cells subjected to the produced nanomaterials showed an increased release of cellular components at $560 \mathrm{~nm}$ as the exposure duration increased. Figure 7 shows that CNMs created at $220 \mathrm{~mJ}$ have the strongest action on bacteria compared to CNMs generated at other laser energy and the effects quickly following nanomaterial treatment. These nanomaterials became more active as the concentration increased with increased laser intensity. Our findings 

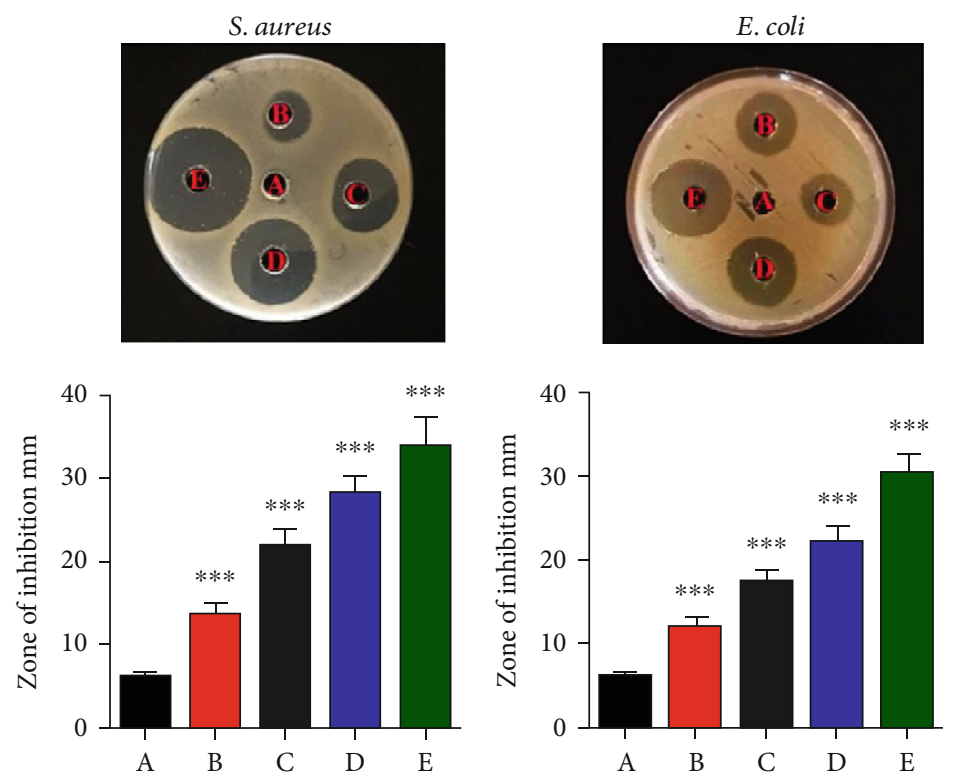

Figure 6: Antibacterial activity of CNPs against bacterial strains: the bacterial strains were treated with $\mathrm{CNPs}$ then incubated at $37^{\circ} \mathrm{C}$ for $24 \mathrm{hr}$. (a) D-W as a negative control; (b-e) CNPs prepared by PLAL at 60, 80, 160, and $220 \mathrm{~mJ}$, respectively. Values are shown as the mean \pm S.D. ${ }^{* * *} p<0.001$ and ${ }^{* * * *} p<0.0001$.

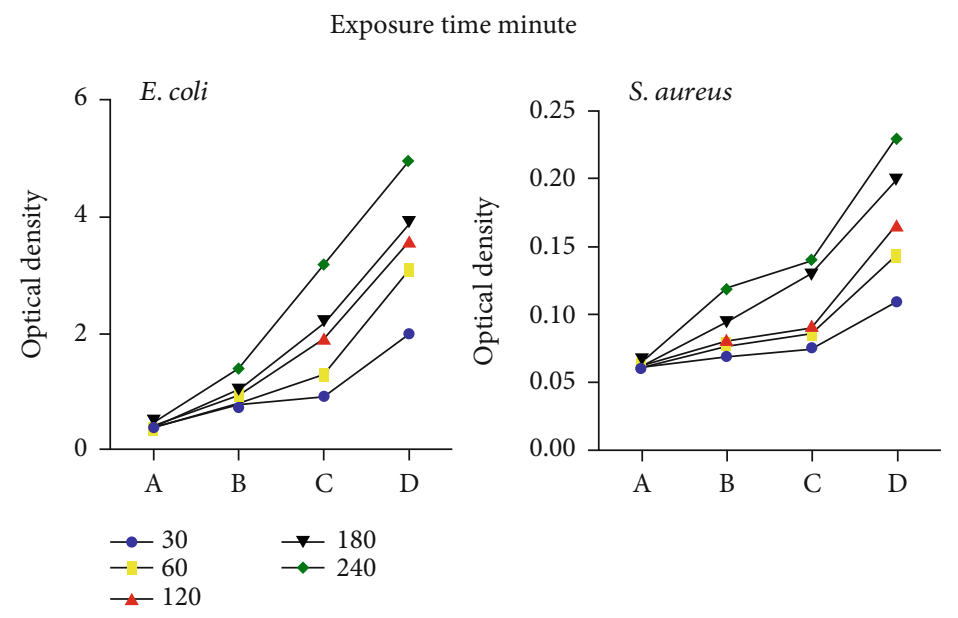

FIGURE 7: Cellular material release of E.coli and S. aureus: (a) control untreated bacteria; (b-d) bacterial strains treated with CNPs prepared at 60,160 , and $220 \mathrm{~mJ}$, respectively.

demonstrated that nanomaterials interacted on the cytoplasmic membrane, increasing membrane permeability [33].

\section{Conclusions}

Aspherical carbon nanomaterials of different sizes have been successfully achieved by pulsed laser ablation in the liquid method. This is proved by FTIR and TEM investigations. UV-Vis measurements showed an increase in the absorbance of carbon nanomaterials with increasing laser energy. CNMs revealed that high antibacterial activity against $E$. coli and $S$. aureus with the best antibacterial impact was for CNMs created at $220 \mathrm{~mJ}$. The difference in the activity is due to the higher concentration and the synergetic effect of carbon NPs.

\section{Data Availability}

The data used to support the findings of this study are included within the article.

\section{Conflicts of Interest}

The authors declare no conflict of interest.

\section{Acknowledgments}

The authors extend their appreciation to the University of Technology, University of Misan, and Taif University (Researchers Supporting project number TURSP-2020/ 274), for their technical support. 


\section{References}

[1] V. K. Varadan, A. S. Pillai, D. Mukherji, M. Dwivedi, and L. Chen, Nanoscience and Nanotechnology in Engineering, World Scientific Publishing Company, 2010.

[2] G. Syrrokostas, G. Leftheriotis, and S. N. Yannopoulos, "Double-layered zirconia films for carbon-based mesoscopic perovskite solar cells and photodetectors," Journal of Nanomaterials, vol. 2019, 11 pages, 2019.

[3] K. S. Khashan, A. Hadi, M. Mahdi, and M. K. Hamid, "Nanosecond pulse laser preparation of InZnO (IZO) nanoparticles NPs for high-performance photodetector," Applied Physics A, vol. 125, no. 1, pp. 1-7, 2019.

[4] X. Cheng, A. Fu, H. Li et al., "Sustainable preparation of copper particles decorated carbon microspheres and studies on their bactericidal activity and catalytic properties," ACS Sustainable Chemistry \& Engineering, vol. 3, no. 10, pp. 2414-2422, 2015.

[5] E. K. Athanassiou, R. N. Grass, and W. J. Stark, "Large-scale production of carbon-coated copper nanoparticles for sensor applications," Nanotechnology, vol. 17, no. 6, pp. 1668-1673, 2006.

[6] X. Bian, T. Guo, J. Zhang et al., "The magnetic nanomaterial biofunctions in cancer diagnosis and therapy," Journal of Nanomaterials, vol. 2021, Article ID 9968166, 9 pages, 2021.

[7] Y. Guo, Z. Wang, H. Shao, and X. Jiang, "Hydrothermal synthesis of highly fluorescent carbon nanoparticles from sodium citrate and their use for the detection of mercury ions," Carbon, vol. 52, pp. 583-589, 2013.

[8] Y. X. Gan, A. H. Jayatissa, Z. Yu, X. Chen, and M. Li, "Hydrothermal synthesis of nanomaterials," Journal of Nanomaterials, vol. 2020, Article ID 8917013, 3 pages, 2020.

[9] K. Koziol, B. O. Boskovic, and N. Yahya, "Synthesis of carbon nanostructures by CVD method," in Carbon and Oxide Nanostructures, pp. 23-49, Springer, 2010.

[10] L. S. Salah, N. Ouslimani, D. Bousba, I. Huynen, Y. Danlée, and H. Aksas, "Carbon nanotubes (CNTs) from synthesis to functionalized (CNTs) using conventional and new chemical approaches," Journal of Nanomaterials, vol. 2021, Article ID 4972770, 31 pages, 2021.

[11] K. S. Khashan, A. I. Hassan, and A. J. Addie, "Characterization of $\mathrm{CuO}$ thin films deposition on porous silicon by spray pyrolysis," Surface Review and Letters, vol. 23, no. 5, p. 1650044, 2016.

[12] P. Asanithi, S. Chaiyakun, and P. Limsuwan, "Growth of silver nanoparticles by DC magnetron sputtering," Journal of Nanomaterials, vol. 2012, Article ID 963609, 8 pages, 2012.

[13] H. Xu, L. Xin, L. Liu et al., "Large area $\mathrm{MoS}_{2} / \mathrm{Si}$ heterojunctionbased solar cell through sol-gel method," Materials Letters, vol. 238, pp. 13-16, 2019.

[14] G. Yang, "Laser ablation in liquids: applications in the synthesis of nanocrystals," Progress in Materials Science, vol. 52, no. 4, pp. 648-698, 2007.

[15] K. Sasaki and N. Takada, "Liquid-phase laser ablation," Pure and Applied Chemistry, vol. 82, no. 6, pp. 1317-1327, 2010.

[16] K. S. Khashan, G. M. Sulaiman, F. A. Abdulameer et al., “Antibacterial activity of $\mathrm{TiO}_{2}$ nanoparticles prepared by one-step laser ablation in liquid," Applied Sciences, vol. 11, no. 10, p. 4623, 2021.

[17] G. Chen, M. H. Hong, T. C. Chong, H. I. Elim, G. H. Ma, and W. Ji, "Preparation of carbon nanoparticles with strong optical limiting properties by laser ablation in water," Journal of Applied Physics, vol. 95, no. 3, pp. 1455-1459, 2004.

[18] M. P. Sk, U. Goswami, S. S. Ghosh, and A. Chattopadhyay, "Cu ${ }^{2+}$-embedded carbon nanoparticles as anticancer agents," Journal of Materials Chemistry B, vol. 3, no. 28, pp. 5673-5677, 2015.

[19] K. S. Khashan, G. M. Sulaiman, R. Mahdi, and A. kadhim, "The effect of laser energy on the properties of carbon nanotube-iron oxide nanoparticles composite prepared via pulsed laser ablation in liquid," Materials Research Express, vol. 5, no. 10, article 105004, 2018.

[20] S. M. Dizaj, A. Mennati, S. Jafari, K. Khezri, and K. Adibkia, "Antimicrobial activity of carbon-based nanoparticles," Advanced pharmaceutical bulletin, vol. 5, no. 1, p. 19, 2015.

[21] L. Escobar-Alarcon, M. E. Espinosa-Pesqueira, D. A. SolisCasados et al., "Two-dimensional carbon nanostructures obtained by laser ablation in liquid: effect of an ultrasonic field," Applied Physics A, vol. 124, no. 2, pp. 1-7, 2018.

[22] S. R. Ji, C. Liu, B. Zhang et al., "Carbon nanotubes in cancer diagnosis and therapy," Cancer, vol. 1806, no. 1, pp. 29-35, 2010.

[23] M. L. Casais-Molina, C. Cab, G. Canto, J. Medina, and A. Tapia, "Carbon nanomaterials for breast cancer treatment," Journal of Nanomaterials, vol. 2018, Article ID 2058613, 9 pages, 2018.

[24] C. Sima, C. Viespe, C. Grigoriu, G. Prodan, and V. Ciupina, "Production of oxide nanoparticles by pulsed laser ablation," Journal of Optoelectronics and Advanced Materials, vol. 10, no. 10, pp. 2631-2636, 2008.

[25] V. Thongpool, S. Denchitcharoen, P. Asanithi, and P. Limsuwan, "Preparation of carbon nanoparticles by long pulsed laser ablation in water with different laser energies," Advanced Materials Research, vol. 214, pp. 402-405, 2011.

[26] E. Vaghri and D. Dorranian, "Effects of green laser fluence on the characteristics of graphene nanosheets synthesized by laser ablation method in liquid nitrogen medium," Optical and Quantum Electronics, vol. 50, no. 2, pp. 1-11, 2018.

[27] M. R. Johan, S. H. M. Suhaimy, and Y. Yusof, "Physico-chemical studies of cuprous oxide $\left(\mathrm{Cu}_{2} \mathrm{O}\right)$ nanoparticles coated on amorphous carbon nanotubes ( $\alpha$-CNTs)," Applied Surface Science, vol. 289, pp. 450-454, 2014.

[28] D. Rosická and J. Šembera, "Changes in the nanoparticle aggregation rate due to the additional effect of electrostatic and magnetic forces on mass transport coefficients," Nanoscale Research Letters, vol. 8, no. 1, pp. 1-9, 2013.

[29] K. Bagga, R. McCann, M. Wang, A. Stalcup, M. Vázquez, and D. Brabazon, "Laser assisted synthesis of carbon nanoparticles with controlled viscosities for printing applications," Journal of Colloid and Interface Science, vol. 447, pp. 263-268, 2015.

[30] D. Reyes-Contreras, M. Camacho-López, M. A. CamachoLópez, S. Camacho-López, R. I. Rodríguez-Beltrán, and M. Mayorga-Rojas, "Influence of the per pulse laser fluence on the optical properties of carbon nanoparticles synthesized by laser ablation of solids in liquids," Optics \& Laser Technology, vol. 74, pp. 48-52, 2015.

[31] M. J. Hajipour, K. M. Fromm, A. Akbar Ashkarran et al., "Antibacterial properties of nanoparticles," Trends in Biotechnology, vol. 30, no. 10, pp. 499-511, 2012. 
[32] A. Al-Jumaili, S. Alancherry, K. Bazaka, and M. V. Jacob, "Review on the antimicrobial properties of carbon nanostructures," Materials, vol. 10, no. 9, p. 1066, 2017.

[33] X.-N. Yang, I. Khan, and S. C. Kang, "Chemical composition, mechanism of antibacterial action and antioxidant activity of leaf essential oil of _Forsythia koreana_deciduous shrub," Asian Pacific Journal of Tropical Medicine, vol. 8, no. 9, pp. 694-700, 2015. 